\title{
Coping response following a diagnosis of breast cancer: A systematic review
}

\author{
Esmat Mehrabi ${ }^{1}$, Sepideh Hajian ${ }^{2}$, Masoomeh Simbar $^{3}$, Mohammad Hoshyari $^{4}$, Farid Zayeri ${ }^{5}$
}

${ }^{1}$ Ph.D. Candidate of Reproductive Health, Student Research Committee, School of Nursing \& Midwifery, Shahid Beheshti University of Medical Sciences, Tehran, Iran

${ }^{2}$ Ph.D. of Reproductive Health, Assistant Professor, Department of Midwifery \& Reproductive Health, School of Nursing \& Midwifery, Shahid Beheshti University of Medical Sciences, Tehran, Iran

${ }^{3}$ Ph.D. of Reproductive Health, Associate Professor, Department of Midwifery \& Reproductive Health, School of Nursing \& Midwifery, Shahid Beheshti University of Medical Sciences, Tehran, Iran

${ }^{4}$ Oncologist, Associate Professor, Shohada-e-Tajrish Hospital, Department of Radiation Oncology, Faculty of Medicine, Shahid Beheshti University of Medical Sciences, Tehran, Iran

${ }^{5}$ Ph.D. of Statistics, Associate Professor, Department of Biostatistics, Shahid Beheshti University of Medical Sciences, Tehran Iran

Type of article: Systematic review

\begin{abstract}
Introduction: Coping with breast cancer is an important health issue that results in adjustments to the disease in survivors. The present systematic review aims to synthesize the evidence about the coping strategies used by women who are primary breast cancer survivors to adjust to their new situations in their lives.

Methods: Searches were conducted using Google Scholar, PubMed, Scopus, Wiley Online Library, and PsycINFO, using the terms "breast cancer," "breast malignancy," "coping strategies," "coping behaviors," and "adjustment" from January 2000 to July 2015. Only relevant studies in English were selected at the end of the search. Only those papers were selected that focused on coping strategies/behaviors that were used by breast cancer survivors.

Results: Searching the electronic databases resulted in 2390 articles. Ultimately, 20 studies met the inclusion criteria of the present study and were included in the review. Two reviewers independently reviewed all relevant articles using the same inclusion criteria. The reviewers completed a quality assessment using the NewcastleOttawa Quality Assessment scales for observational studies. The more frequent coping strategies that patients with breast cancer used in the studies were 1) seeking social support (9 studies), 2) positive reframing and reappraisal behaviors as problem focused strategies (7 studies), 3) religious/spirituality-focused efforts (8 studies), 4) emotional expression as positive emotion-focused strategies (3 studies), and 5) avoidance and distraction as avoidance orientated strategies (6 studies). Women with different ethnicities and educational levels used different coping strategies with breast cancer, and they used different strategies in different phases of the disease.

Conclusion: This systematic review revealed that seeking social support and emotion-focused efforts were the main coping strategies that women with breast cancer diagnosis used, especially in the early phase of breast cancer diagnosis. This information about the coping responses of patients may be useful in designing interventional programs to assist other women in dealing with the various challenges imposed upon them by their illness.
\end{abstract}

Keywords: breast cancer, coping strategies, coping behaviors, adjustment, systematic review

\section{Corresponding author:}

Assistant professor Dr. Sepideh Hajian, Department of Nursing/ Department of Midwifery \& Reproductive Health, School of Nursing \& Midwifery, Shahid Beheshti University of Medical Sciences, Tehran, Iran.

Tel: +98.4133860716, Fax: +98.4133297101, Mobile: +989144142991, E-mail:Hajian74@yahoo.com

Received: August 01, 2015, Accepted: September 09, 2015, Published: December 2015

iThenticate screening: September 09, 2015, English editing: October 28, 2015, Quality control: November 01, 2015

(C) 2015 The Authors. This is an open access article under the terms of the Creative Commons Attribution-NonCommercialNoDerivs License, which permits use and distribution in any medium, provided the original work is properly cited, the use is non-commercial and no modifications or adaptations are made. 


\section{Introduction}

Although breast cancer is the most common cancer among women in both developed and developing countries, it has a higher survival rate than other cancers (1-5). Improvements in the breast cancer survival rate over recent decades have been attributed to progressive developments in early diagnosis and use of adjuvant therapies (6-8), and, according to the findings of various studies, the number of cancer survivors likely will double by $2030(8,9)$. However, the growing number of breast cancer survivors may experience many psychological issues resulting from the disease. In addition, cancer treatment may disrupt the patient's life for a prolonged period. Generally, cancer is considered as a chronic stressor event that influences the patient's life (10-12). It has been reported that a cancer diagnosis impacts different dimensions of patients' lives, including psychological, social, physical, and spiritual dimensions (13), causing long-lasting aftereffects on the quality of life (14). For instance, cancer diagnosis often is accompanied with distress, such as unwanted intrusive thoughts about cancer for patients (15), and it may lead to emotional reactions and psychological challenges, such as anxiety, hopelessness and despair, fear of dying, sense of aloneness, and sexual and body-image problems. In addition, it can impact patients' relationships and change their lives (16-18), thereby causing an overall decrease in the quality of life (19). Women in this situation have to deal and cope with all of these problems to adjust to their diagnosis, and they must deal with the loss of breast tissue, any side effects of adjuvant therapy, and generally with their new life circumstances $(19,20)$. The relationship between coping strategies and quality of life among women with breast cancer has been recognized in numerous publications (21-23) .There are various coping theories that may be used by breast cancer survivors, including Lazarus' theory of appraisal, stress, and coping and Ursin's theory of cognitive-behavioral coping. According to Lazarus' theory of appraisal, stress, and coping, "coping can be defined as constantly changing cognitive and behavioral efforts to manage specific external and/or internal demands that are appreciated as a stressor. "Coping strategies are classified as "problem-focused coping, behavior directed at solving the problem or situation, such as active coping, planning, seeking social (instrumental) support, and suppression of emotions" (24). There are also "emotion-focused coping, behavior directed at changing the emotional reactions to the problem or situations that include various defensive and avoidant strategies" (25). These may include seeking social (emotional) support, turning to religious support, and denial (24). In Ursin's theory of cognitive-behavioral coping, coping is defined as "positive response outcome expectancy implying a generalized positive attitude to a person's capacities to handle s stressful situation, independent of the particular strategy used." In this definition, Ursin indicated that coping efforts are based on a reasonably correct perception of reality, whereas defensive mechanisms are based on distortions of reality (26). As Bernnan reported in the Social-Cognitive Transition model of adjustment to cancer, adjustment is "an ongoing process of learning from, and adapting to the many changes that an individual faces as a result of living with, and receiving treatment for cancer. The degree of adjustment depends on the combined effects of coping responses, social support, and cognitive appraisal of the cancer experience" (27). Since the coping process is highly specific to the person, her culture and her social factors (28), we aimed to synthesize up-to-date evidence about the type of coping strategies used by primary breast cancer survivors.

\section{Material and Methods}

\subsection{Study selection criteria}

The following selection criteria were applied about the type of studies, participants, and coping strategies in this systematic review. Studies published in the English language were included in this systematic review. Only qualitative or quantitative studies with observational designs that had assessed coping strategies to adjust with the breast cancer by survivors were included. The first rationale for this selection was to study the ways of coping that breast cancer patients frequently used, whereas, in the interventional studies, researchers propose or make decisions to do specific intervention(s) to help patients cope with their situations. Second, we attempted to assess whether coping strategies vary among different conditions, such as settings, ethnicity, age, and the stage of the disease. Eligible articles that mentioned implicitly or explicitly any kind of coping strategies used by patients with primary breast cancer were reviewed, and the coping strategies were divided into problem and/or emotion- focused categories according to the essence of the behaviors or efforts.

\subsection{Data collection}

A list of relevant keywords was used to obtain the articles. The keywords included various terms, such as "breast cancer," "breast malignancy," "coping strategies," "coping behaviors," "coping skills," and "adjustment." Then, a systematic literature review was conducted in Google Scholar, PubMed, Scopus, Wiley Online Library, and PsycINFO (from January 2000 to July 2015) and relevant quantitative (except for clinical trials, review articles, and 
meta-analysis studies) and qualitative studies were selected. Finally, we included those papers that addressed the coping strategies that were used by primary breast cancer survivors to achieve adjustment with the disease.

\section{Results}

Electronic database searching resulted in 2390 articles (after removing duplicates), including 1,271 from Google Scholar, 189 from PubMed, 484 from Scopus, 156 from Wiley Online Library, and 290 from PsycINFO. Then, 1,700 articles were excluded because of their research methods (e.g., review articles, meta-analyses, and clinical trials), unrelated titles, text language, or the wrong population. Ultimately, 20 studies met the inclusion criteria of our study and were included in the review. In all, we reviewed 15 quantitative and five qualitative articles. Two reviewers independently reviewed all of the relevant articles using the same inclusion criteria. The reviewers completed a quality assessment using the Newcastle-Ottawa Quality Assessment scales for observational studies. The scores ranged from 0 to 9 , and all of the articles selected for the present study had comparable quality scores; the details of the studies characteristics and Newcastle-Ottawa Quality Assessment scales scoring are presented in Table 1. Sample sizes of the studies that were included varied from 55 to 847 and 19 to 45 in selected quantitative and qualitative studies, respectively. In relation to demographic characteristics, all of the studies except three reported the mean age of patients, which ranged from 43 to 59. Most of the patients were married. Totally, the most common coping strategies that patients with primary breast cancer used in the studies were seeking social support ( 9 studies) (29-37), positive reframing and reappraisal behaviors as problem-focused strategies (7 studies) (31, 32, 40, $43,44,30,46)$, religious /spirituality-focused efforts (8 studies) $(29,31,35,38-41)$, emotional expression as positive emotion-focused strategies ( 3 studies) $(32,42,43)$, and avoidance and distraction as avoidance-orientated strategies (6 studies) $(20,30,33,40,44,45)$. In addition, it was found that emotional coping reactions were stable during the different phases of the disease, including after cancer diagnosis, pre-surgery, and after the adjuvant therapy period, while cognitive coping strategies varied during the aforementioned periods. It seemed that chemotherapy had the strongest influence on the use of coping strategies (46). It also was mentioned that coping response seemed to vary during different phases of the disease due to the decreasing level of anxiety over time (36). Educational level was reported as an important demographic factor that predicted the use of instrumental-based ways of coping and social support, and it was found that higher educational level and lower age were identified as related factors with the use of cognitive defense coping strategies and, therefore, the reduced use of social support (47). In addition, in another study, a positive relationship was found between emotion-based coping response and low educational level (40). In a study that assessed ways that black and white women used to cope with breast cancer, it was identified that most of the black women low socioeconomic status and the late stage of breast cancer at the initial diagnosis. These women were more likely to use coping strategies that included "suppressing emotions," "wishful thinking," and "positive reappraisal," but most white women chose "expressing emotions," "problem-solving," and" escapism," as coping strategies. Also, it was reported that avoidance was somewhat more common among patients with early-stage disease (43). In another study that compared the common coping strategies of African-American, Hispanic, and nonHispanic white women reported that the ways of coping varied across the different ethnicities. In the mentioned study, it was found that religious coping strategies were the most frequent strategy among African-American and Hispanic women, while most non-Hispanic white women used humor to cope with their disease (48).

\section{Discussion}

\subsection{Problem solving skills}

The benefits of problem-focused coping strategies were confirmed by the coping theorists, and these strategies included active acceptance, positive reframing, and turning to religion and spirituality. In addition, problem-focused strategies mostly were used in situations in which the women had a sense of control of the stressor and felt that they could do something constructive about it (24). As we reviewed, Drageset et al., in their qualitative content analyses study, extracted the main themes realted to the ways of coping of 19 women with breast cancer, including step-bystep, pushing away, business as usual, enjoying life, dealing with emotions, preparing for the worst, and positive focus. They noted that it seemed to the main purpose of these patients to avoid being overwhelmed by emotional reactions (49). Anusasananun et al., in a cross-sectional study, explored the common coping strategies of 360 patients in three phases after cancer diagnosis, and they mentioned that positive problem solving mostly was used as their coping response, followed by seeking social support and escape/avoidance (30). Khalili et al., in their crosssectional quantitative study that was performed among 62 Iranian women with a diagnosis of breast cancer, reported that religion, acceptance, planning as problem-focused and self-distraction, avoidance, and denial as an emotionbased way of coping were the most frequent coping responses of patients in their study (40). 
Table 1. Characteristics of Various Related Studies

\begin{tabular}{|c|c|c|c|c|c|}
\hline Main author & Study design & $\mathrm{n}^{1}$ & Measures & Score $^{2}$ & Results (Type of coping strategy used) \\
\hline Reynolds & $\begin{array}{l}\text { Prospective } \\
\text { Cohort }^{3}\end{array}$ & 847 & $\begin{array}{l}\text { modified Folkman and } \\
\text { Lazarus Ways of } \\
\text { Coping questionnaire }\end{array}$ & 8 & Emotion-focused strategies, emotional expression \\
\hline Nosarti & $\begin{array}{l}\text { Prospective } \\
\text { cohort }^{4}\end{array}$ & 74 & $\begin{array}{l}\text { mini mental adjustment } \\
\text { (mini MAC) instrument }\end{array}$ & 7 & fighting spirit, stoic acceptance, social support \\
\hline Henderson & $\begin{array}{l}\text { Cross- } \\
\text { sectional }\end{array}$ & 86 & $\begin{array}{l}\text { Ways of Coping-cancer } \\
\text { (WOC-CA) }\end{array}$ & - & positive reappraisal and seeking social support \\
\hline Hack & $\begin{array}{l}\text { Prospective } \\
\text { cohort }^{5}\end{array}$ & 55 & $\begin{array}{l}\text { Coping response } \\
\text { inventory }\end{array}$ & 8 & $\begin{array}{l}\text { cognitive avoidance strategies, such as passive acceptance } \\
\text { and resignation }\end{array}$ \\
\hline Judulle & $\begin{array}{l}\text { Prospective } \\
\text { cohort }^{6}\end{array}$ & 151 & - & 7 & $\begin{array}{l}\text { instrumental coping ways, distraction and palliative coping } \\
\text { ways }\end{array}$ \\
\hline Elsheshtawy & $\begin{array}{l}\text { Cross- } \\
\text { sectional }\end{array}$ & 56 & Brief cope inventory & - & Emotion-focused strategies, emotional expression \\
\hline $\mathrm{Li}$ & $\begin{array}{l}\text { Cross- } \\
\text { sectional }\end{array}$ & 100 & - & & planning, positive reframing, and self-distraction \\
\hline Danhauer & $\begin{array}{l}\text { Prospective } \\
\text { Longitudinal }^{7}\end{array}$ & 268 & $\begin{array}{l}\text { Ways of coping-cancer } \\
\text { (WOC-CA) }\end{array}$ & 6 & $\begin{array}{l}\text { positive cognitive restructuring, seeking social support, } \\
\text { spirituality, wishful thinking, and making changes }\end{array}$ \\
\hline Hebert & $\begin{array}{l}\text { Prospective } \\
\text { Longitudinal }^{8}\end{array}$ & 86 & $\begin{array}{l}\text { Positive and negative } \\
\text { religious coping and } \\
\text { well-being in women } \\
\text { with breast cancer }\end{array}$ & 7 & $\begin{array}{l}\text { positive religious coping (i.e., partnering with God or } \\
\text { looking to God for strength, support, or guidance) }\end{array}$ \\
\hline Tune-Boyle & $\begin{array}{l}\text { Prospective } \\
\text { Longitudinal }^{9}\end{array}$ & 202 & $\begin{array}{l}\text { Religious cope } \\
\text { questionnaire (RCOPE) }\end{array}$ & 7 & using religion and spirituality \\
\hline Kim & $\begin{array}{l}\text { Cross- } \\
\text { sectional }\end{array}$ & 231 & - & - & self-blame or positive reframing \\
\hline Silva & $\begin{array}{l}\text { Prospective } \\
\text { Longitudinal }^{10}\end{array}$ & 50 & Brief cope inventory & 6 & seeking social support and cognitive strategies \\
\hline Hervatin & $\begin{array}{l}\text { Prospective } \\
\text { Longitudinal }^{11}\end{array}$ & 254 & $\begin{array}{l}\text { standardized coping } \\
\text { manual, the Hannover } \\
\text { Coping Manual (HCM) }\end{array}$ & 6 & emotional coping response \\
\hline Dedert & $\begin{array}{l}\text { Cross- } \\
\text { sectional }\end{array}$ & 57 & Brief cope inventory & 6 & avoidant coping strategies \\
\hline $\begin{array}{l}\text { Anusasanan } \\
\text { un }\end{array}$ & $\begin{array}{l}\text { Cross- } \\
\text { sectional }\end{array}$ & 360 & - & - & $\begin{array}{l}\text { positive problem solving as seeking social support, and } \\
\text { escape/avoidance }\end{array}$ \\
\hline Khalili & $\begin{array}{l}\text { Cross- } \\
\text { sectional }\end{array}$ & 62 & Brief cope inventory & - & $\begin{array}{l}\text { religion, acceptance, self-distraction, planning, active } \\
\text { coping, positive reframing and denial }\end{array}$ \\
\hline Taleghani & $\begin{array}{l}\text { Qualitative } \\
\text { (content } \\
\text { analysis) }\end{array}$ & 19 & Interview & - & $\begin{array}{l}\text { religious approach, thinking about the disease, accepting } \\
\text { the fact of the disease, social and cultural factors and finally } \\
\text { finding support from significant others }\end{array}$ \\
\hline Taleghani & $\begin{array}{l}\text { Qualitative } \\
\text { (Grounded } \\
\text { theory) }\end{array}$ & 45 & Interview & - & $\begin{array}{l}\text { perceived threat to live, religious aspects, supportive } \\
\text { dimensions, will to recover, increase in endurance, barriers } \\
\text { to efforts leading to health, living with the disease with } \\
\text { tolerance }\end{array}$ \\
\hline Drageset & $\begin{array}{l}\text { Qualitative } \\
\text { (content } \\
\text { analysis) }\end{array}$ & 21 & Interview & - & $\begin{array}{l}\text { step-by-step, pushing away, business as usual, enjoying life, } \\
\text { dealing with emotions, preparing for the worst and positive } \\
\text { focus }\end{array}$ \\
\hline Goldblatt & $\begin{array}{l}\text { Qualitative } \\
\text { (content } \\
\text { analysis) }\end{array}$ & 20 & Interview & - & $\begin{array}{l}\text { family comes first, the woman and her family, to expose or } \\
\text { not to expose? That is the dilemma, faith in God as a source } \\
\text { of coping and constructing new meanings following } \\
\text { recovery }\end{array}$ \\
\hline Al azri & $\begin{array}{l}\text { Qualitative } \\
\text { (content } \\
\text { analysis) }\end{array}$ & 19 & Interview & - & $\begin{array}{l}\text { denial, optimism, withdrawal, Islamic beliefs and practices, } \\
\text { and the support of family members and health-care } \\
\text { providers }\end{array}$ \\
\hline
\end{tabular}

1: Sample size; 2; Newcastle-Ottawa quality assessment; 3: Follow up to107 months; 4: Follow-up at pre-diagnosis, 8 weeks after treatment, 9 months after first follow-up; 5: Follow-up at 1.5-6 months after diagnosis and 3years later; 6: Follow-up at pre-surgery and 6 months later; 7: Follow-up at first assessment and 6 months later; 8: Follow-up at study initiation, 8 and 12 months later; 9: Follow-up at surgery, 3 and 12 months later; 10: Follow-up at surgery and chemo-radio therapy and 6 months after treatment; 11: Follow-up after surgery and 12 months later

\subsection{Positive reframing and reappraisal}

A prospective longitudinal assessment of coping strategies was done among younger women with breast cancer by Danhauer et al. in 2009. The participants were 268 women with diagnoses of breast cancer who were studied in the first stage and 246 women in the second stage with the mean age of 43.2. The coping strategies that these patients 
used were assessed through a Ways of Coping-Cancer (WOC-CA) questionnaire. The results indicated that positive cognitive restructuring was the most common strategy that women used, and keeping feelings to oneself was reported as the minimum used coping strategy. They also found that coping strategies varied over time; for instance, they mentioned that seeking social support, spirituality, wishful thinking, and making changes decreased over time among participants (31). In 2007, $\mathrm{Li}$ et al. performed a quantitative study of 100 Chinese women with diagnoses of breast cancer in order to identify the coping strategies they used. They found that the Chinese women with breast cancer mostly used planning, positive reframing, and self-distraction to cope with their illness (45).

\subsection{Seeking social support}

The positive effect of social support on illness-related distress, such as the distress related with a breast cancer diagnosis, and patients' emotional wellbeing is evident in the literature (50). We found evidence that indicated that seeking social support was common among breast cancer patients, especially after the cancer diagnosis and in the pre-surgery stage when the patients were feeling more stress and anxiety $(31,33,34)$. In 2002, Nosarti et al., in their prospective cohort study of 74 women with breast cancer who had a mean age of 59.4, aimed to identify the adjustment ways of these patients. They used the mini mental adjustment to cancer (mini MAC) instrument to identify the strategies that women with primary breast cancer used to adjust to their disease. The patients were assessed at two points, i.e., immediately after their diagnosis of breast cancer diagnosis and three months later. They reported that a fighting spirit and stoic acceptance were the common ways that the patients used to adjust, and it was mentioned that the presence of social support may result in a successful adjustment in first year after the diagnosis (36). In 2011, in another study with the same goal, Silva et al. noted that, when patients were informed about their breast cancer diagnosis, they experienced the greatest anxiety than in the other phases of the disease, and they used ways of coping, such as seeking social support and cognitive strategies, that were linked to the psychological wellbeing of the patients (34). In a cross-sectional study of 86 African-American women with primary breast cancer diagnosis in which strategies for coping with a cancer diagnosis were assessed with the Ways of Coping questionnaire, the results showed that positive reappraisal and seeking social support were used frequently as coping strategies (32). Jadoulle et al. conducted a prospective study that compared the different coping strategies that were used during the acute and chronic phases and their effectiveness with respect to psychological adjustment. In the study, they assessed 151 women at one day before surgery, and they conducted follow-up assessments of 106 of the women six months later. They reported that the patients used the same ways of coping to adjust during the acute and chronic phases and that there was a decrease in the use of instrumental ways of coping and a stability of the distraction and palliative ways of coping in the chronic phase (33). Kim et al. examined the impact of social support on the coping strategies used by women with breast cancer and its impact on their emotional well-being. They assessed the coping strategies of 231 women with breast cancer using the Brief Cope questionnaire and reported that the level of social support had a major impact on the selection of coping strategies (self-blame or positive reframing) (50).

\subsection{Avoidance and distraction}

Avoidance-orientated coping strategies were introduced with two dimensions, i.e., 1) efforts to avoid, deny, and suppress negative emotions and 2) distraction. These strategies mostly were considered to be inferior strategies, but they may provide a short period of temporary relief (51). A prospective cohort study was conducted among women with breast cancer in 2004 by Hack et al. to assess the long-term relationship between coping responses and psychological adjustment to a breast cancer diagnosis. They used the coping response inventory to measures cognitive and behavioral ways of coping according to approach and avoidance coping responses, i.e., logical analysis, positive reappraisal, social support, problem-solving and cognitive avoidance, resigned acceptance, emotional discharge, respectively. The results of their study indicated that patients who used cognitive avoidance strategies, such as passive acceptance and resignation, were at significant risk for poor long-term psychological adjustment (20). Dedert et al. conducted research on the relationships of avoidance coping and cortisol rhythm disruption among 57 breast cancer patients with the mean age of 52. They used the Brief Cope inventory and found that maladaptive psychological responses to breast cancer diagnosis, such as avoidance coping strategies, were associated with cortisol rhythm disruption (44). In addition, a positive relationship was reported in the literature between avoidance coping strategies and pre-surgical distress among women with breast cancer diagnosis $(20,52)$. It was emphasized that avoidance coping strategies may have a positive effect for coping with short-term stressors, but, in the long term, they generally have been related with increased distress (53). 


\subsection{Emotional coping strategies and emotional expression}

Patients often use emotion-focused coping strategies when they feel that the stressor is something they must endure (24). Coping through emotional ways, such as expressing emotions, was found to be related with higher quality of life among patients with breast cancer (54). Reynolds et al. performed a prospective cohort study among a large population of patients with breast cancer in the U.S. and reported that there was a positive association between emotion-based coping strategies and emotional expression with the rate of survival (43). Another study, which was conducted among 57 Egyptian women with breast cancer diagnosis using the Brief Cope inventory, found that acceptance, religion, and emotional support were the most frequently-used coping strategies (42). The same results were reported by Hervatin et al., who also emphasized the stability of the emotional coping response of these patients over the time of the disease (46). The expression of emotions was identified as having a positive effect on patients' psychological status $(20,49,54)$, but it may have a unfavorable impact on the breast cancer patients' sense of coping (49).

\subsection{Religious and spirituality - focused efforts}

The positive impact of religious beliefs and spirituality was reported on patient illness adjustment (41). In our review, two studies included measures of religious/spiritual coping strategies and their impact on the general wellbeing and adjustment to the illness among women with breast cancer. It was mentioned that most women used positive religious coping (i.e., partnering with God or looking to God for strength, support, or guidance), and a minority used negative religious coping (i.e., feeling abandoned by or anger at God), which may predict poor mental health in women with breast cancer (39). The same results were reported in another study, and it was reported that using religion and spirituality as resources and ways of coping was common among patients, and it also may have a role in the long-term adjustment to cancer by providing emotional comfort and a sense of hope (41). There were limited literature references with qualitative designs that studied coping strategies that women with primary breast cancer diagnosis have used to adjust to the disease during the past 15 years. In 2006, Talegani et al. performed a qualitative study to assess the coping behaviors of women in Iran who had an early diagnosis of breast cancer. They conducted semi-structured interviews with 19 women with primary breast cancer diagnosis and realized that the frequently used coping efforts included resorting to religious beliefs, thinking about the disease, accepting the reality of the disease, and finally seeking support from significant others. They stated that the most prevalent coping strategies among women were positive thinking and religious faith (35). The same researcher conducted qualitative research with the grounded theory design and performed 45 interviews with patients with primary breast malignant tumor in different phases of the disease to investigate patients' experiences with adjustment to the situation. The study's findings encompassed eight themes from the patients' experiences of adjustment, i.e., "perceived threat to live," "religious aspects," "supportive dimensions," "will to recover," "increase in endurance," "barriers to efforts leading to health," "living with the disease with tolerance," and "inhibitors and facilitators of tolerance"(37). In the same qualitative study that was done among Omani women with breast cancer diagnosis in 2013, the results showed that the patients used various coping strategies, including denial, optimism, withdrawal, Islamic beliefs and practices, and the support of family members and healthcare providers. It is recognized that Islamic beliefs and practices were common coping strategies that women used (29). The coping strategies also were studied by Goldblatt et al. among Arab (Muslim and Christian) women with breast cancer diagnosis. The experiences of the women were categorized as family comes first, the woman and her family. That is the dilemma, whether faith in God is a source of coping and constructing new meanings after recovering from cancer (38).

\section{Conclusions}

This review indicated that seeking social support was the main coping strategy that women with primary breast cancer diagnosis used, especially at the early phase following the diagnosis of breast cancer. In addition, women in the early stage of the disease often tended to use religious strategies to cope with their disease due to enhanced anxiety and distress during the period immediately after the diagnosis. Some demographic factors are indicative of the ways patients confront their cancer, such as the patient's educational level and ethnicity. In addition, the coping strategies that patients use in different phases of the disease vary, and patients often used different approaches to deal with the situation. The relationship between the use of coping strategies and the patients' psychological adjustment has been confirmed in various studies. The use of coping strategies is recommended because they empower patients who are confronted with a cancer diagnosis and have an important role in their psychological adjustment to the illness and treatment-related complications. The knowledge about coping response of patients to cancer may be useful in designing intervention programs aimed to assist them in dealing with the various challenges 
imposed upon them by their illness. In addition, cultural differences should be considered in these programs because culture has an impact on the choice of and use of coping strategies.

\section{Conflict of Interest:}

There is no conflict of interest to be declared.

\section{Authors' contributions:}

All authors contributed to this project and article equally. All authors read and approved the final manuscript.

\section{References}

1) Babu GR, Samari G, Cohen SP, Mahapatra T, Wahbe RM, Mermash S, et al. Breast cancer screening among females in Iran and recommendations for improved practice: a review. Asian Pac J Cancer Prev. 2011; 12(7): 1647-55, PMID: 22126539

2) Sharif F, Abshorshori N, Tahmasebi S, Hazrati M, Zare N, Masoumi S. The effect of peer-led education on the life quality of mastectomy patients referred to breast cancer-clinics in Shiraz, Iran 2009. Health Qual Life Outcomes. 2010;8(1):74. doi: 10.1186/1477-7525-8-74, PMID: 20653966, PMCID: PMC2919455

3) Somi MH, Farhang S, Mirinezhad SK, Naghashi S, Seif-Farshad M, Golzari M. Cancer in East Azerbaijan, Iran: results of a population-based cancer registry. Asian Pac J Cancer Prev. 2008; 9(2): 327-30, PMID: 18712985

4) Koch L, Jansen L, Brenner H, Arndt V. Fear of recurrence and disease progression in long - term ( $\geqslant 5$ years) cancer survivors - a systematic review of quantitative studies. Psycho Oncol. 2013; 22(1): 1-11. doi: 0.1002/pon.3022, PMID: 22232030.

5) Knobf MT, Ferrucci LM, Cartmel B, Jones BA, Stevens D, Smith M, et al. Needs assessment of cancer survivors in Connecticut. J Cancer Surviv. 2012; 6(1): 1-10. doi: 10.1007/s11764-011-0198-2, PMID: 21984194, PMCID: PMC3274636

6) Youlden DR, Cramb SM, Dunn NA, Muller JM, Pyke CM, Baade PD. The descriptive epidemiology of female breast cancer: an international comparison of screening, incidence, survival and mortality. Cancer Epidemiol. 2012; 36(3): 237-48. doi: 10.1016/j.canep.2012.02.007, PMID: 22459198

7) Chopra I, Kamal KM. A systematic review of quality of life instruments in long-term breast cancer survivors. Health Qual Life Outcome. 2012; 10(1): 10-4. doi: 10.1186/477-7525, PMID: 22289425, PMCID: PMC3280928.

8) Campbell HS, Sanson-Fisher R, Turner D, Hayward L, Wang XS, Taylor-Brown J. Psychometric properties of cancer survivors' unmet needs survey. Support Care Cancer. 2011; 19(2): 221-30. doi: 10.1007/s00520-009-0806-0, PMID: 20099001

9) Zucca A, Lambert SD, Boyes AW, Pallant JF. Rasch analysis of the Mini-Mental Adjustment to Cancer Scale (mini-MAC) among a heterogeneous sample of long-term cancer survivors: A cross-sectional study. Health Qual Life Outcome. 2012; 10(1): 1-12. doi: 10.1186/477-7525-10-55, PMID: 22607052, PMCID: PMC3487859.

10) Koh KB. Somatization and Psychosomatic Symptoms. New york. Springer; 2013. doi: 10.1007/978-14614-7119-6

11) Kwak M, Zebrack BJ, Meeske KA, Embry L, Aguilar C, Block R, et al. Prevalence and predictors of post - traumatic stress symptoms in adolescent and young adult cancer survivors: a 1 - year follow - up study. Psycho Oncol. 2013; 22(8): 1798-806. doi: 10.002/pon.3217, PMID: 23135830.

12) Abbey G, Thompson SB, Hickish T, Heathcote D. A meta - analysis of prevalence rates and moderating factors for cancer - related post - traumatic stress disorder. Psycho Oncol. 2014; 24(4): 371-81. doi: 10.1002/pon.3654, PMID: 25146298, PMCID: PMC4409098.

13) MacDonald BH. Quality of life in cancer care: patients' experiences and nurses' contribution. Eur J Oncol Nurs. 2001; 5(1): 32-41. doi: 10.1054/ejon.2000.0118,, PMID: 12849046

14) Foley KL, Farmer DF, Petronis VM, Smith RG, McGraw S, Smith K, et al. A qualitative exploration of the cancer experience among long - term survivors: comparisons by cancer type, ethnicity, gender, and age. Psychooncology. 2006; 15(3): 248-58. doi: 10.1002/pon.942, PMID: 15940742

15) Bleiker EM, Pouwer F, van der Ploeg HM, Leer J-WH, Adèr HJ. Psychological distress two years after diagnosis of breast cancer: frequency and prediction. Patient education and counseling. Patient Educ Couns . 2000; 40(3): 209-17. doi: 10.1016/S0738-3991(99)00085-3 
16) Fu MR, Xu B, Liu Y, Haber J. 'Making the best of it': Chinese women's experiences of adjusting to breast cancer diagnosis and treatment. J Adv Nurs. 2008; 63(2): 155-65. doi: 10.1111/j.1365-2648.2008.04647.x, PMID: 18537844

17) Zabora J, BrintzenhofeSzoc K, Curbow B, Hooker C, Piantadosi S. The prevalence of psychological distress by cancer site. Psycho - Oncology. Psychooncology. 2001; 10(1): 19-28. doi: 10.1002/10991611(200101/02)10:1<19::AID-PON501>3.0.CO;2-6, PMID: 11180574

18) Garlick M, Wall K, Corwin D, Koopman C. Psycho-spiritual integrative therapy for women with primary breast cancer. J Clin Psychol Med Settings. 2011; 18(1): 78-90. doi: 10.1007/s10880-011-9224-9, PMID: 21344265

19) Al - Azri M, Al - Awisi H, Al - Moundhri M. Coping With a Diagnosis of Breast Cancer - Literature Review and Implications for Developing Countries. Breast J. 2009; 15(6): 615-22. doi: 10.1111/j.15244741.2009.00812.x, PMID: 19686231

20) Hack TF, Degner LF. Coping responses following breast cancer diagnosis predict psychological adjustment three years later. Psycho - Oncology. 2004; 13(4): 235-47. doi: 10.1002/pon.739, PMID: 15054728

21) Sehlen S, Song R, Fahmüller H, Herschbach P, Lenk M, Hollenhorst H, et al. Coping of cancer patients during and after radiotherapy-a follow-up of 2 years. Oncology Research and Treatment. 2003; 26(6): 55763. doi: 10.1159/000074151

22) Avis NE, Crawford S, Manuel J. Quality of life among younger women with breast cancer. J Clin Oncol. 2005; 23(15): 3322-30. doi: 10.1200/JCO.2005.05.130, PMID: 15908646

23) Sears SR, Stanton AL, Danoff-Burg S. The yellow brick road and the emerald city: benefit finding, positive reappraisal coping and posttraumatic growth in women with early-stage breast cancer. Health Psychol. 2003; 22(5): 487. doi: 10.1037/0278-6133.22.5.487, PMID: 14570532

24) Carver CS, Scheier MF, Weintraub JK. Assessing coping strategies: a theoretically based approach. J Pers Soc Psychol. 1989; 56(2): 267. doi: 10.1037/0022-3514.56.2.267, PMID: 2926629

25) Lazarus RS. Stress and emotion: A new synthesis: Springer Publishing Company; 2006.

26) Ursin H. Expectancy and activation: an attempt to systematize stress theory. Neurobiological approaches to human disease. 1988;313.

27) Brennan J. Adjustment to cancer-coping or personal transition? Psycho - Oncology. 2001; 10(1): 1-18. doi: 10.1002/1099-1611(200101/02)10:1<1::AID-PON484>3.0.CO;2-T, PMID: 11180573

28) Zeidner M, Endler NS. Handbook of coping: Theory, research, applications: John Wiley \& Sons; 1996.

29) Al-Azri MH, Al-Awisi H, Al-Rasbi S, Al-Moundhri M. Coping with a diagnosis of breast cancer among Omani women. J Health Psychol. 2014; 19(7): 836-46. doi: 10.1177/1359105313479813, PMID: 23520353

30) Anusasananun B, Pothiban L, Kasemkitwatana S, Soivong P, Trakultivakorn H. Coping Behaviors and Predicting Factors among Breast Cancer Survivors During Each Phase of Cancer Survivorship. Pacific Rim Int Nurs Res. 2013; 17(2): 148-66.

31) Danhauer SC, Crawford SL, Farmer DF, Avis NE. A longitudinal investigation of coping strategies and quality of life among younger women with breast cancer. J Behav Med. 2009; 32(4): 371-9. doi: 10.1007/s10865-009-9211-x, PMID: 19308716

32) Henderson PD, Fogel J, Edwards QT. Coping strategies among African American women with breast cancer. Southern Online Journal of Nursing Research. 2003; 3(4): 1-20.

33) Jadoulle V, Rokbani L, Ogez D, Maccioni J, Lories G, Bruchon-Schweitzer M, et al. Coping and adapting to breast cancer: a six-month prospective study. Bulletin du cancer. 2006; 93(7): 10067-72.

34) Silva SM, Crespo C, Canavarro MC. Pathways for psychological adjustment in breast cancer: A longitudinal study on coping strategies and posttraumatic growth. Psychol Health. 2012; 27(11): $1323-41$. doi: 10.1080/08870446.2012.676644, PMID: 22490001

35) Taleghani F, Yekta ZP, Nasrabadi AN. Coping with breast cancer in newly diagnosed Iranian women. J Adv Nurs. 2006; 54(3): 265-72. doi: 10.1111/j.1365-2648.2006.03808_1.x, PMID: 16629910.

36) Nosarti C, Roberts JV, Crayford T, McKenzie K, David AS. Early psychological adjustment in breast cancer patients: a prospective study. J Psychosom Res. 2002; 53(6): 1123-30. doi: 10.1016/S00223999(02)00350-1. PMID: 12479995

37) Taleghani F, Yekta ZP, Nasrabadi AN, Käppeli S. Adjustment process in Iranian women with breast cancer. Canc Nurs. 2008; 31(3): 32-41. doi: 10.1097/01.NCC.0000305720.98518.35, PMID: 18453870. 
38) Goldblatt H, Cohen M, Azaiza F, Manassa R. Being within or being between? The cultural context of Arab women's experience of coping with breast cancer in Israel. Psycho - Oncology. 2013; 22(4): 869-75. doi: 10.1002/pon.3078, PMID: 22473753

39) Hebert R, Zdaniuk B, Schulz R, Scheier M. Positive and negative religious coping and well-being in women with breast cancer. J Palliat Med. 2009; 12(6): 537-45. doi: 10.1089/jpm.2008.0250, PMID: 19508140, PMCID: PMC2789454

40) Khalili N, Farajzadegan Z, Mokarian F, Bahrami F. Coping strategies, qualitay of life and pain in women with breast cancer. Iran J Nurs Midwifery Res. 2013; 18(2): 105-11, PMID: 23983738, PMCID: PMC3748564

41) Thuné - Boyle I, Stygall J, Keshtgar M, Davidson T, Newman S. Religious coping strategies in patients diagnosed with breast cancer in the UK. Psycho - Oncology. 2011; 20(7): 771-82. doi: 10.1002/pon.1784, PMID: 20878874

42) Elsheshtawy EA, Abo-Elez WF, Ashour HS, Farouk O, Elzaafarany ME. Coping Strategies in Egyptian Ladies with Breast Cancer. Breast cancer: basic and clinical research. Breast Cancer (Auckl). 2014; 8: 97 102. PMCID: PMC4055407

43) Reynolds P, Hurley S, Torres M, Jackson J, Boyd P, Chen VW. Use of coping strategies and breast cancer survival: results from the Black/White Cancer Survival Study. Am J Epidemiol. 2000; 152(10): 940-9. doi: 10.1093/aje/152.10.940, PMID: 11092436

44) Dedert E, Lush E, Chagpar A, Dhabhar FS, Segerstrom SC, Spiegel D, et al. Stress, coping, and circadian disruption among women awaiting breast cancer surgery. Ann Behav Med. 2012; 44(1): 10-20. doi: 10.1007/s12160-012-9352-y, PMID: 22450856

45) Li J, Lambert VA. Coping strategies and predictors of general well - being in women with breast cancer in the People's Republic of China. Nurs Health Sci. 2007; 9(3): 199-204. doi: 10.1111/j.14422018.2007.00325.x, PMID: 17688478

46) Hervatin R, Sperlich S, Koch-Giesselmann H, Geyer S. Variability and stability of coping in women with breast cancer. Support Care Cancer. 2012; 20(10): 2277-85. doi: 10.1007/s00520-011-1334-2, PMID: 22124528

47) Drageset S. Psychological distress, coping and social support in the diagnostic and preoperative phase of breast cancer. 2012: University of Bergen. Available from: https://bora.uib.no/bitstream/handle/1956/6139/Dr\%20thesis_Sigrunn\%20Drageset.pdf?sequence=1.; 2005 .

48) Culver JL, Arena PL, Antoni MH, Carver CS. Coping and distress among women under treatment for early stage breast cancer: comparing african americans, hispanics and non - hispanic whites. Psycho - Oncology. 2002; 11(6): 495-504. doi: 10.1002/pon.615, PMID: 12476431

49) Drageset S, Lindstrøm TC, Underlid K. Coping with breast cancer: between diagnosis and surgery. J Adv Nurs. 2010; 66(1): 149-58. doi: 10.1111/j.1365-2648.2009.05210.x, PMID: 20423441

50) Kim J, Han JY, Shaw B, McTavish F, Gustafson D. The Roles of Social Support and Coping Strategies in Predicting Breast Cancer Patients' Emotional Well-being Testing Mediation and Moderation Models. J Health Psychol. 2010; 15(4): 543-52. doi: 10.1177/1359105309355338, PMID: 20460411, PMCID: PMC3145334

51) Vingerhoets A. Assessment in behavioral medicine: Routledge; 2013.

52) David D, Montgomery GH, Bovbjerg DH. Relations between coping responses and optimism-pessimism in predicting anticipatory psychological distress in surgical breast cancer patients. Pers Individ Dif. 2006; 40(2): 203-13. doi: 10.1016/j.paid.2005.05.018, PMID: 19079761, PMCID: PMC2600560

53) Taylor SE, Stanton AL. Coping resources, coping processes, and mental health. Annu Rev Clin Psychol. 2007; 3: 377-401. doi: 10.1146/annurev.clinpsy.3.022806.091520, PMID: 17716061

54) Stanton AL, Danoff-Burg S, Cameron CL, Bishop M, Collins CA, Kirk SB, et al. Emotionally expressive coping predicts psychological and physical adjustment to breast cancer. J Consult Clin Psychol. 2000; 68(5): 875. doi: 10.1037/0022-006X.68.5.875, PMID: 11068973 